\title{
The multifaceted nature of HIV latency
}

\author{
Caroline Dufour, ${ }^{1}$ Pierre Gantner, ${ }^{1}$ Rémi Fromentin, ${ }^{2}$ and Nicolas Chomont ${ }^{1,2}$ \\ 'Department of Microbiology, Infectiology and Immunology and ² Centre de Recherche du Centre Hospitalier, Université de Montréal, Montreal, Quebec, Canada.
}

\begin{abstract}
Although antiretroviral therapies (ARTs) potently inhibit HIV replication, they do not eradicate the virus. HIV persists in cellular and anatomical reservoirs that show minimal decay during ART. A large number of studies conducted during the past 20 years have shown that HIV persists in a small pool of cells harboring integrated and replication-competent viral genomes. The majority of these cells do not produce viral particles and constitute what is referred to as the latent reservoir of HIV infection. Therefore, although HIV is not considered as a typical latent virus, it can establish a state of nonproductive infection under rare circumstances, particularly in memory $\mathrm{CD4}^{+} \mathrm{T}$ cells, which represent the main barrier to HIV eradication. While it was originally thought that the pool of latently infected cells was largely composed of cells harboring transcriptionally silent genomes, recent evidence indicates that several blocks contribute to the nonproductive state of these cells. Here, we describe the virological and immunological factors that play a role in the establishment and persistence of the pool of latently infected cells and review the current approaches aimed at eliminating the latent HIV reservoir.
\end{abstract}

\section{Distinguishing HIV latency and HIV persistence}

More than 20 years after the discovery of combination antiretroviral therapy (ART), complete eradication of HIV infection has not yet been achieved, with the notable exception of a few rare cases $(1,2)$. While ART blocks new cycle of viral replication and partially restores immune functions, it is not a cure. In the vast majority of people living with HIV (PLHIV), interrupting ART leads to rapid viral load rebound, usually within a few weeks after treatment cessation (3), even if treatment was initiated during the first weeks of infection and maintained for years (4). These clinical observations indicate that HIV persists in reservoirs that are largely insensitive to antiretroviral drugs. Viral reservoirs have been defined as cell types or anatomical sites in association with which replication-competent forms of the virus persist with more stable kinetic properties than in the main pool of actively replicating virus (5, 6). This definition implies that any infected cell with a half-life of more than 2 days, which corresponds to the average half-life of productively infected cells $(7,8)$, may represent a reservoir for HIV. Using ultrasensitive methods to quantify and characterize traces of virus persisting in PLHIV and receiving fully effective ART, two types of viral reservoirs that could both contribute to HIV persistence have been identified (Figure 1).

A first reservoir is thought to be maintained by residual viral replication during ART, which has been attributed to the suboptimal diffusion of antiretroviral drugs in lymphoid tissues (9), allowing the virus to replicate at low levels. Whether this phenomenon occurs in the majority of individuals on ART is still controversial (10). Ongoing viral replication during ART is supported by a few studies that have demonstrated viral evolution in virally suppressed individuals (11) and perturbation in the reservoir following

Authorship note: CD and PG contributed equally.

Conflict of interest: The authors have declared that no conflict of interest exists.

Copyright: @ 2020, American Society for Clinical Investigation.

Reference information: J Clin Invest. 2020;130(7):3381-3390.

https://doi.org/10.1172/JCI136227. treatment intensification $(12,13)$, suggesting that ART is not fully efficient. The fact that HIV-specific $\mathrm{CD}^{+} \mathrm{T}$ cells may not be able to access anatomical sites in which ongoing replication occurs, for example in the germinal center of second lymphoid organs $(14,15)$ or in immune-privileged organs such as testis (16), may also contribute to residual levels of viral replication during ART. In addition, HIV-specific cytotoxic T lymphocytes have limited killing capacity $(17,18)$, possibly due to their persistent exhaustion status (19) and/or to immunosuppressive environments (20), which may permit the replenishment of the HIV reservoir.

While residual levels of viral replication may occur in a fraction of individuals on ART, particularly those who received less efficient antiviral drugs and whose immune functions were not restored by ART, multiple studies failed to identify strong evidence for ongoing viral replication in individuals receiving new-generation antiviral drugs (21-24). Although the replenishment of the HIV reservoir through de novo infection during ART cannot be excluded, its demonstration is difficult, and the recent data indicating that the bulk of the reservoir is established near the time of ART initiation argue against it (25).

The second type of viral reservoir that contributes to HIV persistence is a small pool of latently infected cells that persists for decades in PLHIV receiving ART (26-28). Latently infected cells can be defined as cells harboring integrated and intact proviruses that do not actively produce infectious virions, but that have the capacity to do so upon stimulation (5). Even though HIV can establish latency, it differs from herpesviruses, which produce viral proteins that are specifically required for the establishment and maintenance of a viral latency program. The capacity of HIV to lie dormant within specific types of cells and at extremely low frequencies suggests that it can establish latency under rare circumstances. The first evidence that HIV can establish a nonproductive state of infection in CD4 $4^{+}$T cells was demonstrated in 1995, before the implementation of combined ART in PLHIV: Chun et al. isolated resting $\mathrm{CD} 4^{+} \mathrm{T}$ cells from the blood of individuals with active HIV infection and observed that a small fraction of these 


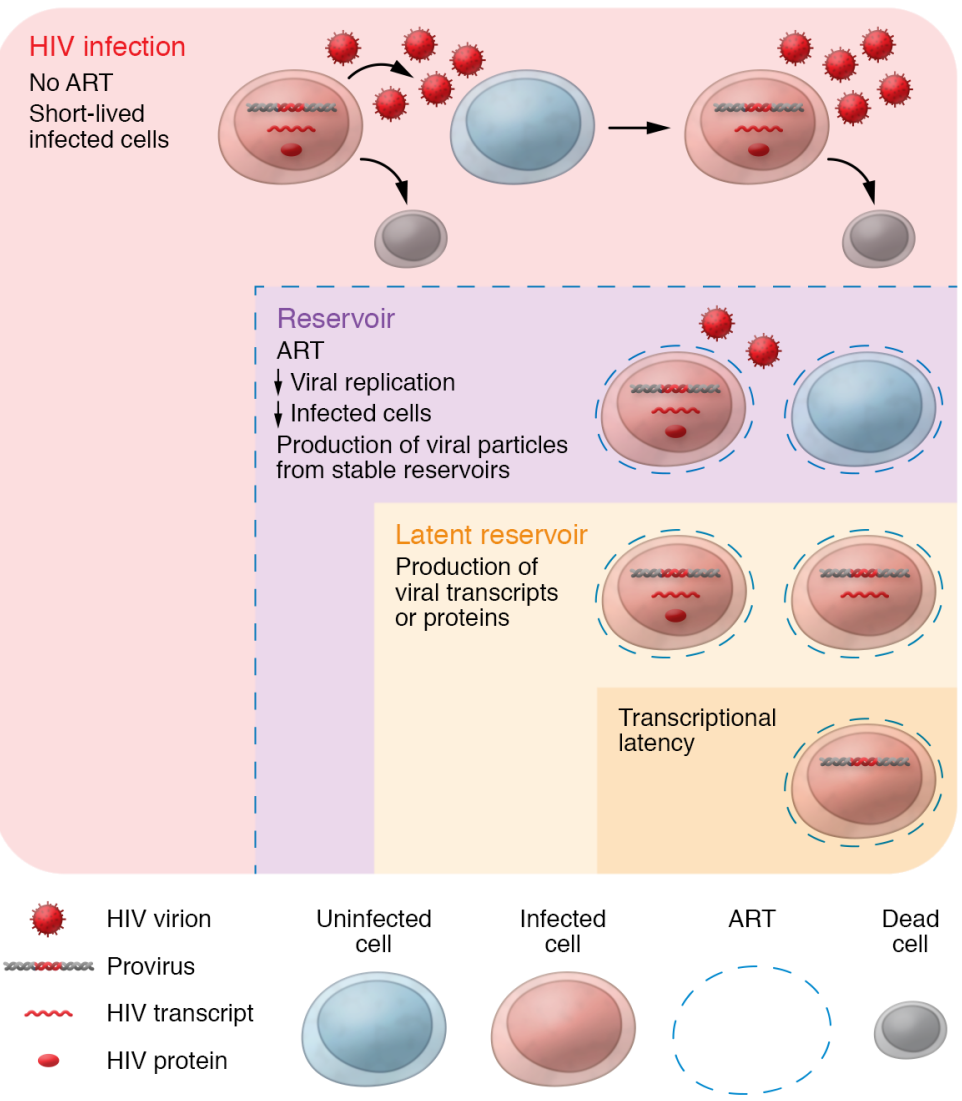

Figure 1. Distinguishing HIV persistence and HIV latency. During untreated HIV infection, the majority of infected cells are short-lived: HIV viremia is sustained by a dynamic process involving continuous rounds of de novo infection. Initiation of ART (blue dashed lines) leads to a dramatic reduction in the levels of viral replication and in the frequency of infected cells. Residual viremia persists and can originate from low levels of ongoing replication or, more likely, from the continuous production of viral particles from stable reservoirs. The majority of infected cells in PLHIV on ART do not produce viral particles and are defined as latently infected cells. Although the production of spliced transcripts or viral proteins is rare, a relatively large fraction of these cells produce short, abortive viral transcripts. Complete silencing of HIV genomes may also occur when epigenetic regulators repress the LTR transcriptional activity. cells harbored integrated HIV genomes and could produce viral particles upon stimulation ex vivo (29). The fraction of resting $\mathrm{CD}^{+} \mathrm{T}$ cells with integrated provirus is similarly low in blood and lymph nodes and much lower than the frequency of cells harboring unintegrated viral genomes, which are much shorter-lived (30) but can complicate the measurement of the HIV reservoir during untreated HIV infection. In 1997, the implementation of effective ART in PLHIV revealed the clinical importance of this pool of latently infected cells: three studies reported the presence of a small number of persistently infected cells harboring replicationcompetent HIV in individuals on suppressive ART (26-28). Although these cells are extremely rare (around 1 in 1 million resting $\mathrm{CD}^{+} \mathrm{T}$ cells), the reservoir is long-lived, with an estimated half-life of 44 months $(31,32)$, indicating that ART alone will not eradicate the pool of latently infected cells in a lifetime.

Although it was rapidly apparent that this small pool of persistently infected cells would represent a formidable challenge to HIV eradication, more than 20 years later, the precise nature of the HIV reservoir remains unclear. In addition to the diversity in the tissues and cellular subsets in which HIV persists during ART (discussed below), a variety of nonproductive infection states have been described. The assessment of the transcriptional and translational status of persistent HIV proviruses in virally suppressed individuals challenges our definition of HIV latency. Whereas viral latency is often associated with transcriptional latency (i.e., the lack of transcription from the HIV promoter), an increasing number of studies indicate that complete silencing of the HIV promoter is a rare event $(33,34)$. Therefore, a relatively large fraction and possibly the majority of latently infected cells (as defined by cells that do not produce viral particles) may express low levels of short viral transcripts $(34,35)$. Although these abortive transcripts are frequently produced, they rarely elongate enough to generate complete or spliced transcripts (36). Accordingly, production of viral proteins by latently infected cells appears to be rare $(37,38)$. This suggests that several blocks may contribute to the inability of persistently infected cells to produce infectious viral particles, including blocks in elongation of transcription (36), nuclear export (39), multiple splicing (34), and translation, as detailed below.

Even if the majority of persistently infected cells do not produce viral particles spontaneously, low levels of viremia, below the limit of detection of commercial assays, can be measured in the majority of PLHIV on ART $(40,41)$. The presence of residual viremia indicates that a small fraction of persistently infected cells produces viral particles at a given time. As mentioned above, residual viremia is unlikely to originate from low levels of residual replication, but rather from the production of viral particles from a stable pool of persistently infected cells. Indeed, the small population of viral particles circulating in individuals on ART is dominated by a predominant plasma clone not found in the latent reservoir, indicating that these virions are unlikely to replenish the persistent reservoir $(42,43)$. Residual levels of viremia show a two-phase decay, suggesting that it may arise from at least two cell compartments, one in which viral production decays over time and a second in which viral production remains stable for at least 7 years (44). The source of residual viremia remains currently unknown. The existence of this "active reservoir" is an additional challenge to the development of effective curative strategies, since it represents a likely cause of viral rebound upon ART interruption. 


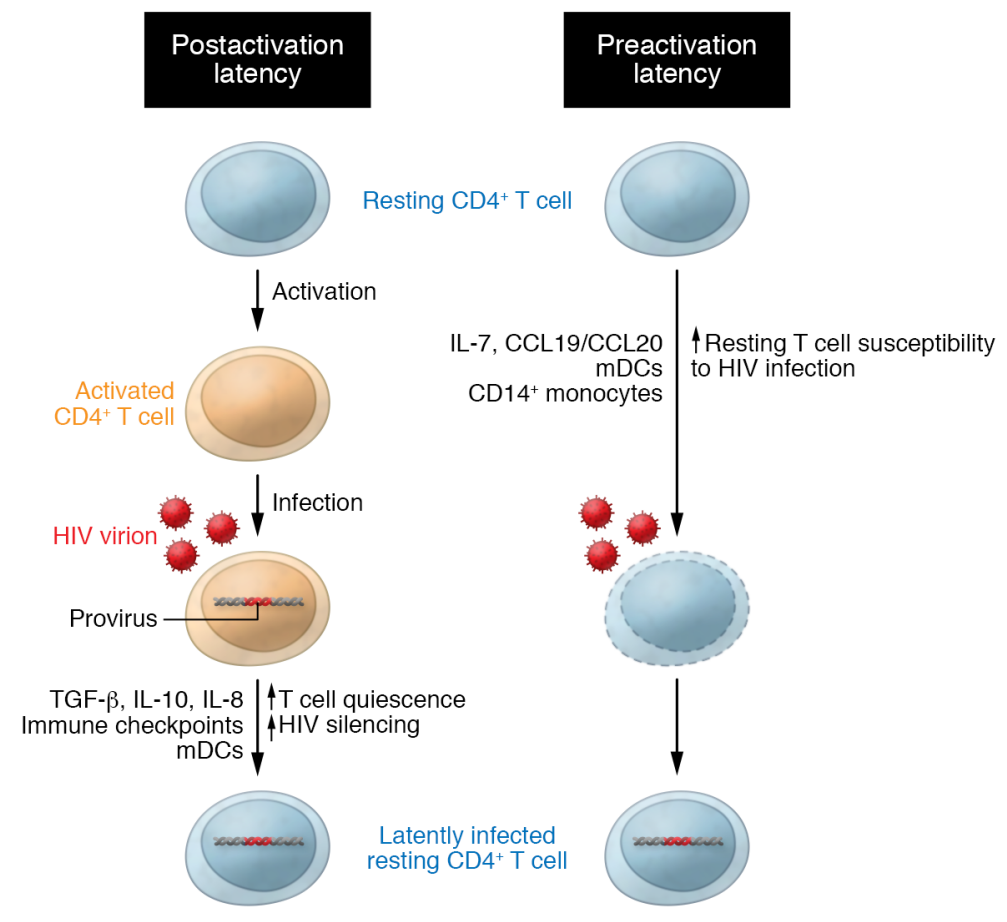

Figure 2. Models for the establishment of HIV latency. Postactivation latency refers to a phenomenon by which activated productively infected $C D 4^{+} T$ cells revert back to a quiescent state, which is accompanied by the silencing of the HIV promoter. In preactivation latency, resting $C D 4^{+} T$ cells, which are usually refractory to HIV infection, become permissive and establish latency directly (i.e., in the absence of $\mathrm{T}$ cell activation).

longed therapy may either prevent the establishment or accelerate the clearance of viral reservoirs. Altogether, these observations indicate that early ART may not entirely prevent the establishment of the reservoir, but may accelerate its decay.

For obvious reasons, human studies of early reservoir establishment are much more complicated to conduct: very recently infected individuals are difficult to identify, and access to tissues from PLHIV poses logistical and ethical challenges. The unique case of an individual infected during the initiation of pre-exposure prophylaxis who initiated ART only 10 days after infection is informative:

Although the HIV reservoir is usually defined as a pool of cells harboring replication-competent (and therefore intact) genomes, several lines of evidence indicate that defective proviruses, even if not capable of replication, have the ability to produce viral transcripts and viral proteins $(45,46)$. Albeit indirectly, these defective genomes likely contribute to sustained inflammation and $\mathrm{T}$ cell activation even after prolonged ART $(47,48)$, which may in turn contribute to HIV persistence by promoting the proliferation of infected T cells $(49,50)$.

\section{Establishment of HIV latency}

When, where, and how HIV latency is established is still the object of intensive investigations. In the absence of ART, activated $\mathrm{CD}_{4}{ }^{+} \mathrm{T}$ cells represent the main target for HIV and die rapidly upon infection $(7,8)$. Only a minute fraction of these cells survives and enters the pool of persistent and long-lived latently infected cells (51). Although the timing of the establishment of the pool of latently infected cells in humans remains unclear, several groups recently used nonhuman primate models of HIV infection (rhesus macaques infected with SIV) to precisely determine the duration of untreated infection needed to establish persistent infection (52, 53). In these studies, ART was initiated at different times after infection, and the size of the pool of persistent SIV-infected cells during prolonged suppressive therapy was evaluated by measurement of markers of viral persistence and by analytical treatment interruption. Whitney et al. (52) reported that initiation of ART 3 days after SIV inoculation blocked the emergence of viral RNA and proviral DNA in peripheral blood. Nevertheless, after discontinuation of ART following 24 weeks of fully suppressive therapy, virus rebounded in all animals (with a moderate but statistically significant delay in comparison with animals initiating ART later). In contrast, Okoye et al. (53) observed that ART initiation at days 4 and 5 followed by suppressive therapy for 2 years led to viral control and possibly eradication of the virus, indicating that very early and proeven if HIV could not be detected in blood and tissues from this individual after 2 years of therapy, he experienced viral rebound 225 days after ART cessation, suggesting that a persistent reservoir was established in less than 10 days (54). In line with this observation, initiation of ART in eight individuals at the earliest stage of diagnosable HIV infection (Fiebig I stage) drastically reduced the size of the pool of HIV-infected cells but did not prevent viral rebound upon ART initiation $(4,55)$. A recent and larger study of acutely treated PLHIV revealed that the pool of infected cells rapidly increases and reaches its maximal size in tissues in the first 2 weeks of infection, i.e., before seroconversion (56). Interestingly, the majority of these early targets are rapidly cleared upon ART initiation, suggesting that infected cells have a greatear ability to persist after peak viremia. This is in line with the study by Okoye et al. in nonhuman primates (53) and suggests that the early reservoir may be relatively labile. The virological and immunological mechanisms supporting this phenomenon remain to be determined.

As mentioned above, circulating cells are not the unique site of HIV replication and are unlikely to represent the most favorable environment for the establishment of HIV latency. Less than $2 \%$ of the total body $\mathrm{T}$ cells are found in peripheral blood. Therefore, it is not surprising that HIV-infected cells are found in multiple tissues after years of ART $(57,58)$, particularly in gut and lymph nodes, and at lower frequencies in the spleen, liver, lung, central nervous system, and bone marrow (59). Since gut-associated lymphoid tissue (GALT) and lymph nodes are particularly enriched in persistently infected cells during ART $(56,60)$, lymphoid tissues may represent a favorable environment for the establishment of viral latency.

The anatomical location and the timing of the emergence of persistently infected cells offer a glimpse into some of the mechanisms contributing to the establishment of HIV latency (Figure 2). Latently infected cells are mainly resting memory $\mathrm{CD} 4^{+}$ $\mathrm{T}$ cells $(26-28,30,61)$. The transition from an activated state to quiescence may offer a narrow window of opportunity that per- 


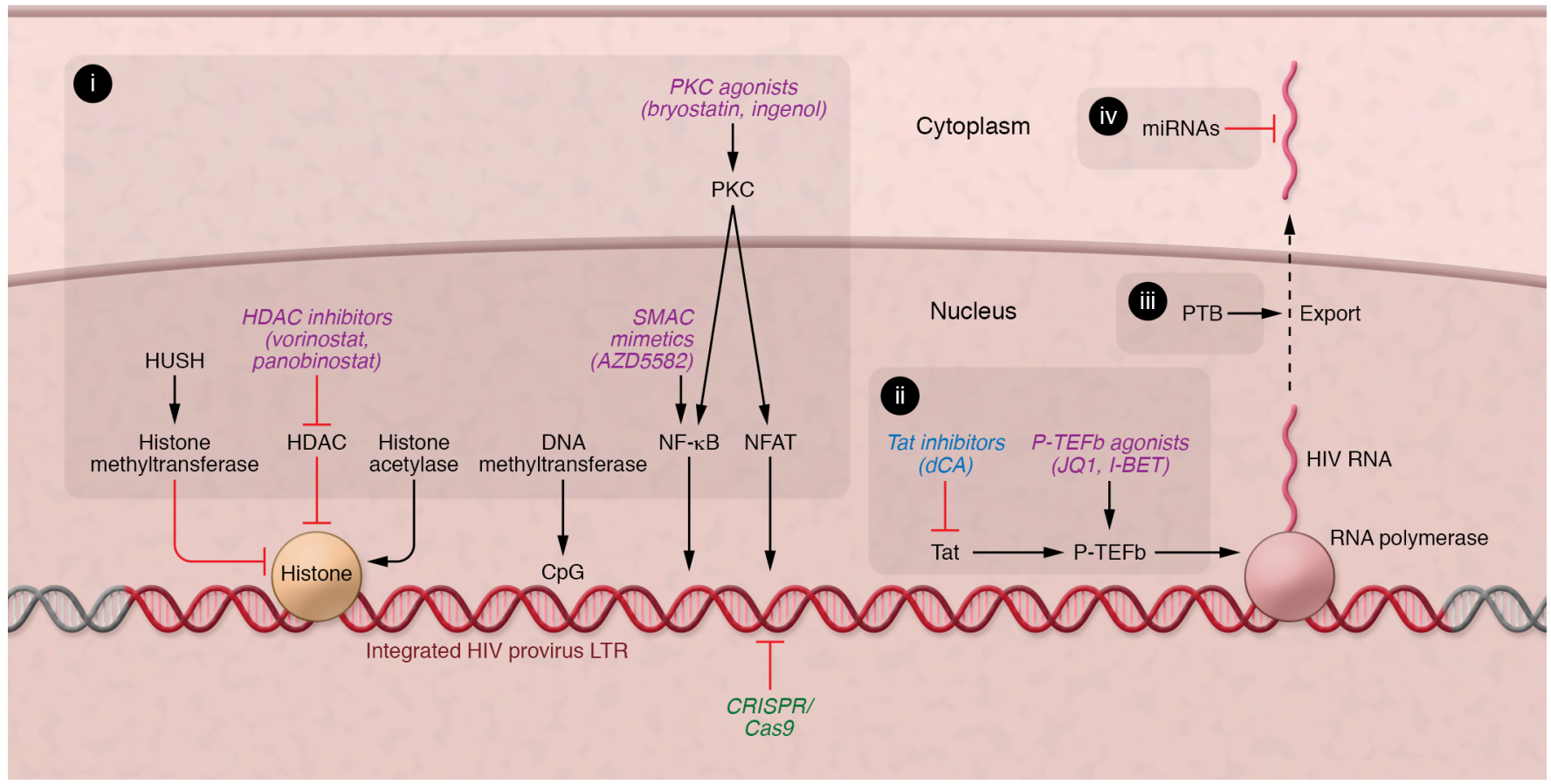

Figure 3. Mechanisms and targets of HIV latency. HIV silencing is regulated by key control elements acting on (i) HIV transcription initiation (histone acetylation/deacetylation, histone and DNA methylation, transcription factors), (ii) HIV transcription elongation (positive transcription elongation factor b [P-TEFb] and viral protein Tat), (iii) HIV RNA export (polypyrimidine tract-binding protein [PTB]), and (iv) HIV RNA degradation (miRNAs). Pathways promoting HIV expression are shown with black arrows, whereas those inhibiting HIV expression are shown in red. These pathways can be targeted in vivo (in italics) in order to reverse HIV latency (latency-reversing agents [LRAs], purple), promote HIV latency (latency-promoting agents [LPAs], blue), or edit the HIV genome (CRISPR/Cas9, green).

mits HIV silencing and persistence of the infected cells. During the contraction phase of the immune response, when the antigen load decreases and activated cells transition from an effector to a memory phenotype, a rare subset of cells are still permissive to HIV infection but also are transcriptionally programmed to become quiescent, a state that is favorable to HIV latency (62). The role of cytokines such as TGF- $\beta$, IL-10, and IL- 8 in this phenomenon has been confirmed in in vitro experiments using polarized $\mathrm{CD}^{+} \mathrm{T}$ cells (63). Additionally, immune checkpoint molecules are known to dampen $\mathrm{T}$ cell activation and may consequently favor HIV latency. PD-1, LAG-3, and TIGIT were initially identified as markers of HIV-infected cells during ART (64-66). Further investigations demonstrated the active role of PD-1 in silencing HIV transcription $(67,68)$. Interestingly, the presence of monocytes or myeloid dendritic cells (mDCs) in coculture with activated HIV-infected T cells may favor their transition to a postactivation state of latency, highlighting the role of cell-to-cell contact in the establishment of HIV latency $(69,70)$.

Several lines of evidence suggest that latency may also be directly established in resting $\mathrm{CD}^{+} \mathrm{T}$ cells. Although resting $\mathrm{CD}^{+} \mathrm{T}$ cells are refractory to productive infection as a result of numerous blocks in the HIV replication cycle, cell-cell interactions increase their susceptibility (71-73). Soluble factors are also known to increase the susceptibility of resting $\mathrm{CD} 4^{+} \mathrm{T}$ cells to latent HIV infection. For instance, IL-7, a cytokine involved in T cell homeostasis, modulates the activity of the restriction factor SAMHD1 and increases the permissiveness of resting $\mathrm{CD} 4^{+} \mathrm{T}$ cells to HIV infection (74, 75). Similarly, CCL19 and CCL20, two chemokines involved in the trafficking of cells to lymph nodes and GALT, enhance HIV infection of resting $\mathrm{CD} 4^{+} \mathrm{T}$ cells by modifying the actin cytoskeleton, thereby increasing nuclear entry and integration of the viral DNA (76). Furthermore, the anatomical localization of resting $\mathrm{CD}^{+}{ }^{+} \mathrm{T}$ cells may influence their susceptibility to HIV infection: $\mathrm{CD} 4^{+} \mathrm{T}$ cells isolated from lymphoid tissues (spleen and tonsil), which display an intermediate level of activation, are more permissive to HIV infection and latency (77). A model in which cell-to-cell transmission from activated, productively infected $\mathrm{CD} 4^{+} \mathrm{T}$ cells to resting $\mathrm{CD} 4^{+} \mathrm{T}$ cell leads to latent infection may mimic the spread of HIV infection in anatomical sites with a high density of T cells, such as germinal centers in lymph nodes (78). All these studies support an alternative model in which direct nonproductive infection of resting $\mathrm{CD} 4^{+} \mathrm{T}$ cells may result in viral latency.

Recent data also suggest that the strength of the T cell receptor engagement could influence the transcriptionally active versus latent status of the provirus. Intermediate and low signals predispose cells toward latent infections that are refractory to reversal (79). Evans et al. demonstrated that interactions between antigen-presenting cells (APCs) and resting $\mathrm{CD} 4^{+} \mathrm{T}$ cells favor latency establishment (80). Signals from mDCs induce downregulation of the NF-кB pathways and upregulation of Krüppel-like factor 6 (KLF6) in $\mathrm{CD}^{+} \mathrm{T}$ cells, thereby promoting $\mathrm{T}$ cell quiescence. In vitro, only $\mathrm{mDCs}$ and $\mathrm{CD} 14^{+}$monocytes expressing specific cell surface molecules involved in cell-cell interaction have the ability to induce HIV latency in CD4 ${ }^{+}$T cells (69), suggesting that cell-cell 
interactions modify the transcription network of $\mathrm{CD} 4^{+} \mathrm{T}$ cells to establish a prolatency environment in a cell-specific manner.

\section{Locations of HIV reservoirs}

In addition to blood, persistently infected cells are found in the lymph nodes (64), gut (81-83), central nervous system (84), lungs $(85)$, bone marrow $(86,87)$, and genital tract $(16,88-90)$. Recently, a study performed with tissues collected from six PLHIV postmortem revealed the presence of HIV DNA in all 28 tissues analyzed (58). If HIV DNA can be easily detected in most parts of the body at relatively high frequencies, these measures overestimate the size of the reservoir. In the blood, replication-competent proviruses are present in only 1 in 1 million $\mathrm{CD}^{+} \mathrm{T}$ cells $(26,27)$, whereas HIV DNA quantification typically measures frequencies that are two to three orders of magnitude higher. This difference is due to a large proportion of HIV genomes presenting various defects preventing them from replicating (91). In the blood, defective proviruses represent $95 \%-98 \%$ of the viral genomes (92), and these defects accumulate rapidly in the course of infection (93). Only a few studies have investigated the presence of intact or replication-competent genomes in tissues from PLHIV $(30,58,64,94)$. Therefore, the exact contribution of these anatomical reservoirs to the pool of persistently infected cells remains largely unknown.

It is generally accepted that memory $\mathrm{CD} 4^{+} \mathrm{T}$ cells represent the major cellular reservoir for HIV, at least quantitatively (30, 61). To a lesser extent, cellular reservoirs may also comprise myeloid cells such as monocytes, tissue-resident macrophages, and follicular dendritic cells (reviewed in refs. 95, 96), although whether these cells represent long-lived reservoirs for the virus after prolonged ART remains unclear (97-99). The $\mathrm{CD}^{+} \mathrm{T}$ cell compartment can be divided into subsets endowed with different functional, proliferative, and survival capacities. Several studies have shown that the less differentiated memory subsets, including stem cell memory (Tscm) and central memory $(\mathrm{Tcm})$, are particularly enriched in $\operatorname{HIV}$ genomes during $\operatorname{ART}(61,100,101)$. These cells possess a high proliferation potential and, following antigen stimulation, can give rise to effector memory $\mathrm{T}$ (Tem) cells $(102,103)$. While Tcm cells have been shown to highly contribute to the pool of cells harboring integrated HIV DNA (61), the Tem subset may encompass the majority of intact and potentially replication-competent proviruses (104). In addition to these memory subsets, specific functionally polarized subsets of $\mathrm{CD} 4^{+}$ $\mathrm{T}$ cells have also been shown to be enriched in persistent HIV: blood- and gut-derived Th17 cells are enriched in HIV proviruses (105), and a large portion of replication-competent viral genomes are found within the Th1 and T follicular helper cell (Tfh) subsets $(64,92)$. HIV also preferentially persists in tissue-resident memory T cells (106). The diversity of the cellular reservoirs for HIV, which are characterized by distinct mechanisms of maintenance, adds another level of complexity to the development of HIV eradication strategies $(38,107,108)$.

\section{Molecular mechanisms of HIV latency}

Unlike herpesviruses, HIV does not encode for proteins specific for a latency program. Nonetheless, HIV expression is under the control of molecular components of the infected cell that can induce and/or maintain a nonproductive state of infection (Figure 3). A first mechanism that governs HIV expression is linked to the location of the integration site. HIV proviruses are more frequently integrated in introns of actively transcribed gene $(109,110)$. Integration in the same orientation of actively transcribed genes can impair HIV expression through transcriptional interference (111). HIV integration site may also influence the degree of latency, with deeply latent proviruses being mostly located in non-genic regions (112).

As for transcriptionally active cellular genes, the HIV genome needs to be accessible to the transcriptional machinery, and this access is epigenetically controlled. The HIV promoter is wrapped around nucleosomes nuc- $\mathrm{O}$ and nuc-1 (113). These histone complexes are posttranslationally modulated by epigenetic marks to induce HIV transcription through acetylation $(114,115)$, or silencing through deacetylation $(116,117)$ and methylation (118). In addition, two $\mathrm{CpG}$ islands found in the HIV long terminal repeat (LTR) can be methylated and consequently maintain viral repression (119). The protein complex HUSH also contributes to the epigenetic control of HIV transcription by silencing proviruses harboring $\mathrm{H} 3 \mathrm{~K} 9 \mathrm{me} 3$ methylation marks when the viral proteins vpr and vpx are not expressed $(120,121)$.

In addition, initiation of HIV transcription requires the binding of the cellular transcription factor NF- $\mathrm{BB}$ to the viral promoter (122). Notably, binding sites for the ubiquitous transcription factors Sp1 and AP-1 and for the immune cell-specific NFAT (123) are also present in the LTR. The elongation of HIV transcripts is relatively inefficient in latently infected cells: a considerable amount of short, abortive transcripts lacking the poly(A) tail are detected in latently infected cells from PLHIV on ART (36). NF- $\mathrm{KB}$ plays an additional role by recruiting the elongation factor P-TEFb (124). However, this recruitment is mostly accomplished by the viral protein Tat once it has been translated (125). In addition to transcriptional regulation, the lack of viral production by infected cells can also be attributed to post-transcriptional blocks. Unspliced viral RNA and as many as 40 different singly and multiply spliced RNAs can be transcribed from a single genome (126). A defect in splicing may contribute to the absence of viral proteins, particularly Tat, which is required for expression of all viral transcripts (34). Furthermore, viral RNAs accumulate in the nucleus of latently infected cells, and this defect in RNA export can be reverted by overexpressing the polypyrimidine tract-binding protein (PTB) in resting cells (39). Finally, microRNA can prevent the translation of coding viral RNA by complementary homology. HIV infection is known to impact the miRNA profile of the cell (127). Cellular miRNA, such as miR-132 (128), can promote HIV replication indirectly by silencing proteins involved in transcriptional regulation. Conversely, latency can be maintained by miRNAs directly targeting the $3^{\prime}$ end of HIV transcripts (miR-28, miR-125b, miR-150, miR-223, miR-382) (129) or the HIV nef RNA (miR-29a) (130). Altogether, these studies highlight the multiplicity of the cellular mechanisms that contribute to the nonproductive state of HIV-infected cells during ART.

\section{Maintenance of latently infected cells by cell proliferation}

As discussed above, the majority of persistently infected cells do not produce viral particles during ART. These latently infected cells are maintained through both cell survival signals, preventing HIV-infected cells from death, and cell division signals, promoting 
the expansion of HIV-infected clones $(61,131)$. Several studies over the past 10 years have clearly demonstrated that clonal expansions occur in the persistent HIV reservoir, as shown by the duplication of partial and near-full-length HIV genomes and/or integration sites $(92,109,110,112,132-139)$. These infected clones wax and wane during ART, resulting in a dynamic pool of infected cells over time $(133,137,140,141)$. Several mechanisms contribute to the dynamics of the HIV reservoir (142): (a) antigen-driven proliferation (134, $143,144)$, (b) homeostatic proliferation $(61,137,145)$, and/or (c) HIV integration-induced proliferation $(109,110,146)$. Although antigen-driven proliferation has been proposed as the major driver of HIV persistence, all three phenomena likely coexist $(142,147)$.

\section{Targeting HIV latency in vivo}

The ultimate objective of an HIV cure is to eradicate all infected cells from the body or to induce durable immune control of the HIV reservoir (reviewed in ref. 148). Here, we will focus on strategies that target the pool of latently infected cells and that consist of either depletion of these cells or permanent silencing of the integrated proviruses.

The shock-and-kill strategy combines the reactivation of latent proviruses ("shock") and the elimination of the resulting productively infected cells ("kill"), with the hypothesis that viral cytopathic effects or clearance of virus-expressing cells by the immune system will reduce the size of the latent reservoir (149, 150). To induce proviral expression, a large number of latencyreversing agents (LRAs) have been identified (151). These agents need to be potent enough to reactivate efficiently most HIV proviruses without inducing a cytokine release syndrome, which would result in major adverse events. This fine balance is a major obstacle to the success of these strategies: the administration of an antiCD3 antibody together with IL-2, although efficient at reactivating HIV, was highly toxic in PLHIV on ART (152).

LRAs can be divided in several pharmacological classes and can be used alone or in combinations: histone deacetylase inhibitors (HDACis [refs. 117, 153-156]), protein kinase C (PKC) agonists (157-160), P-TEFb agonists (161, 162), second mitochondriaderived activator of caspase (SMAC) mimetics (163-165), and Tolllike receptor (TLR) agonists $(166,167)$. These agents target different cellular pathways, all of which are nonspecific to the induction of HIV transcription. In fact, most of these LRAs were originally developed for other indications. For instance, the HDACi suberanilohydroxamic acid had been shown to be active against leukemia and breast cancer cell lines $(168,169)$. Similarly, the fusion inhibitor maraviroc, which was originally used as an antiretroviral drug, has been shown to induce HIV transcription through the NF- $\mathrm{B}$ pathway in vivo and may also be used as an LRA (170).

The majority of clinical trials conducted so far mostly used HDACis such as valproic acid (171-175), vorinostat (176-178), panobinostat (179), and romidepsin (180), and demonstrated a transient increase in cell-associated HIV RNA and/or residual plasma viremia in virally suppressed PLHIV. Low doses of the PKC agonist bryostatin were also recently tested in a phase I clinical trial and did not result in an induction of HIV transcription in vivo (181). Disappointingly, none of these studies resulted in a significant decrease in the size of the HIV reservoir in individuals on ART. Several factors may explain these negative results: (a) LRAs may have differential effects between tissues (177); (b) LRAs are not equally efficient in all populations of $\mathrm{CD}^{+} \mathrm{T}$ cells, suggesting that they may be largely ineffective in some cellular reservoirs $(107,108)$; (c) effector cells may be lacking at sites of active viral production such as lymph nodes $(14,15,17)$; (d) the persistent immune exhaustion of $\mathrm{CD}^{+} \mathrm{T}$ cells may not allow the efficient elimination of productively infected cells (182); (e) some LRAs, particularly HDACis, have been shown to impair cytotoxic effector responses (183) and antigen presentation by APCs (184), which could hamper viral reservoir elimination; and (f) productively infected cells may be inherently resistant to immunemediated killing through the expression of prosurvival factors (185).

Several improvements have been proposed to increase the efficacy of LRAs at reactivating latent HIV proviruses in individuals on ART, including the use of LRA combinations, development of new pharmacological classes of LRAs, and enhancement of cytotoxic immune responses (186). Overall, a better understanding of the effects of LRAs in vivo is needed to improve future shock-and-kill strategies.

The opposite of shock-and-kill strategies, block-and-lock strategies are aimed at promoting permanent silencing of HIV proviruses using latency-promoting agents (LPAs). This approach is based on the hypothesis that HIV latency can be induced in an irreversible way, which would prevent viral rebound upon ART cessation. These LPAs act by inhibiting viral or cellular proteins involved in HIV transcription (187). The best-described LPA is didehydro-cortistatin A (dCA), a Tat inhibitor $(188,189)$ shown to decrease viral RNA in cells and tissues and delay viral rebound upon ART cessation in a humanized mouse model (189). The efficacy of LPAs at preventing viral rebound in HIV-infected individuals has not been investigated yet.

Another approach to reduce the reservoir of latently infected cells is to permanently inactivate the integrated proviruses. Given the recent development of the CRISPR/Cas9 system, the excision or inactivation of the HIV genome is now theoretically possible (190). Inactivation of the provirus by targeting of different conserved HIV sequences was tested in several in vitro models. Although the approach was originally promising $(191,192)$, it resulted in a long-term escape caused by HIV DNA mutations in the targeted sequences, preventing single-guide RNA recognition (193-196). Nonetheless, HIV proviral genome excision by CRISPR/Cas9 in a humanized mouse model resulted in promising observations (197). Future studies are warranted to determine whether the combination of multiple-guide RNAs targeting different HIV variants and/or genome sites could prevent viral escape.

\section{Conclusions}

In individuals on ART, HIV persists at low levels in several tissues and multiple cellular subsets and displays different states of transcriptional and translational activities. The multifaceted aspect of these HIV reservoirs complicates their analysis and the development of efficient therapeutic strategies to target them. The relative contributions of these reservoirs, from cells that continuously produce low levels of viral particles during ART to the extreme case of fully transcriptionally silent genomes, remain unclear. More importantly, the clinically relevant reservoir that causes viral rebound upon ART cessation has not been identified yet. 
Given the large diversity of the cells in which HIV persists and the multiple molecular mechanisms contributing to viral persistence, studies conducted on bulk populations of cells are unlikely to reveal targetable mechanisms to cure HIV infection. The recent development of single-cell approaches to study the transcriptome and proteome of individual HIV-infected cells $(38,198,199)$ will certainly help in this endeavor.

\section{Acknowledgments}

The authors are grateful to the individuals who volunteered to participate in the studies reviewed in this article. This work was supported by the Canadian Institutes for Health Research (CIHR; 364408, 377124, and 385806), the Delaney AIDS Research Enter- prise (DARE) to Find a Cure (UM1AI126611), the réseau SIDA et maladies infectieuses du Fonds de Recherche du Québec Santé (FRQS), and the Canadian HIV Cure Enterprise (CanCURE) from the CIHR (team grant HB2-164064). NC is supported by Research Scholar Career Awards of the Quebec Health Research Fund (FRQS, 253292). CD is supported by a doctoral fellowship from the CIHR (413313). PG is supported by a postdoctoral fellowship from the CIHR (415209).

Address correspondence to: Nicolas Chomont, Centre de Recherche du CHUM, 900 rue Saint-Denis, R09-430, Montreal, Quebec H2X OA9, Canada. Phone: 514.890 .8000 ext. 31266; Email: nicolas.chomont@umontreal.ca.
1. Hütter G, et al. Long-term control of HIV by CCR5 Delta32/Delta32 stem-cell transplantation. NEnglJMed. 2009;360(7):692-698.

2. Gupta RK, et al. HIV-1 remission following CCR5 $\Delta 32 / \Delta 32$ haematopoietic stem-cell transplantation. Nature. 2019;568(7751):244-248.

3. Davey RT, et al. HIV-1 and T cell dynamics after interruption of highly active antiretroviral therapy (HAART) in patients with a history of sustained viral suppression. Proc Natl Acad Sci U S A. 1999;96(26):15109-15114.

4. Colby DJ, et al. Rapid HIV RNA rebound after antiretroviral treatment interruption in persons durably suppressed in Fiebig I acute HIV infection. Nat Med.2018;24(7):923-926.

5. Blankson JN, Persaud D, Siliciano RF. The challenge of viral reservoirs in HIV-1 infection. Annu Rev Med. 2002;53:557-593.

6. Eisele E, Siliciano RF. Redefining the viral reservoirs that prevent HIV-1 eradication. Immunity. 2012;37(3):377-388.

7. Ho DD, Neumann AU, Perelson AS, Chen W, Leonard JM, Markowitz M. Rapid turnover of plasma virions and CD4 lymphocytes in HIV-1 infection. Nature. 1995;373(6510):123-126.

8. Wei X, et al. Viral dynamics in human immunodeficiency virus type 1 infection. Nature. 1995;373(6510):117-122.

9. Fletcher CV, et al. Persistent HIV-1 replication is associated with lower antiretroviral drug concentrations in lymphatic tissues. Proc Natl Acad Sci U S A. 2014;111(6):2307-2312.

10. Kearney MF, et al. Ongoing HIV replication during ART reconsidered. Open Forum Infect Dis. 2017;4(3):ofx173.

11. Lorenzo-Redondo R, et al. Persistent HIV-1 replication maintains the tissue reservoir during therapy. Nature. 2016;530(7588):51-56.

12. Buzón MJ, et al. HIV-1 replication and immune dynamics are affected by raltegravir intensification of HAART-suppressed subjects. Nat Med. 2010;16(4):460-465.

13. Hatano $\mathrm{H}$, et al. Increase in 2-long terminal repeat circles and decrease in D-dimer after raltegravir intensification in patients with treated HIV infection: a randomized, placebo-controlled trial. J Infect Dis. 2013;208(9):1436-1442.

14. Connick E, et al. CTL fail to accumulate at sites of HIV-1 replication in lymphoid tissue. J Immunol. 2007;178(11):6975-6983.
15. Fukazawa $Y$, et al. B cell follicle sanctuary permits persistent productive simian immunodeficiency virus infection in elite controllers. Nat Med. 2015;21(2):132-139.

16. Jenabian MA, et al. Immune tolerance properties of the testicular tissue as a viral sanctuary site in ART-treated HIV-infected adults. AIDS. 2016;30(18):2777-2786

17. Reuter MA, et al. HIV-specific CD $8^{+} \mathrm{T}$ cells exhibit reduced and differentially regulated cytolytic activity in lymphoid tissue. Cell Rep. 2017;21(12):3458-3470.

18. Kiniry BE, et al. Predominance of weakly cytotox ic, T-bet ${ }^{\mathrm{Low}}$ Eomes $^{\mathrm{Neg}} \mathrm{CD} 8^{+} \mathrm{T}$-cells in human gastrointestinal mucosa: implications for HIV infection. Mucosal Immunol. 2017;10(4):1008-1020.

19. Tauriainen J, et al. Perturbed $\mathrm{CD} 8^{+} \mathrm{T}$ cell TIGIT/ CD226/PVR axis despite early initiation of antiretroviral treatment in HIV infected individuals. Sci Rep. 2017;7:40354

20. Damouche A, et al. High proportion of PD-1expressing $\mathrm{CD} 4^{+} \mathrm{T}$ cells in adipose tissue constitutes an immunomodulatory microenvironment that may support HIV persistence. Eur I Immunol. 2017;47(12):2113-2123.

21. Gandhi RT, et al. The effect of raltegravir intensification on low-level residual viremia in HIV-infected patients on antiretroviral therapy: a randomized controlled trial. PLoS Med. 2010;7(8):e1000321.

22. Dinoso JB, et al. Treatment intensification does not reduce residual HIV-1 viremia in patients on highly active antiretroviral therapy. Proc Natl Acad Sci U S A. 2009;106(23):9403-9408.

23. Hatano $\mathrm{H}$, et al. A randomized, controlled trial of raltegravir intensification in antiretroviral-treated, HIV-infected patients with a suboptimal CD4+ T cell response. J Infect Dis. 2011;203(7):960-968.

24. McMahon D, et al. Short-course raltegravir intensification does not reduce persistent low-level viremia in patients with HIV-1 suppression during receipt of combination antiretroviral therapy. Clin Infect Dis. 2010;50(6):912-919.

25. Abrahams MR, et al. The replication-competent HIV-1 latent reservoir is primarily established near the time of therapy initiation. Sci Transl Med. 2019;11(513):eaaw5589.

26. Wong JK, et al. Recovery of replication-competent HIV despite prolonged suppression of plas- ma viremia. Science. 1997;278(5341):1291-1295.

27. Finzi $D$, et al. Identification of a reservoir for HIV-1 in patients on highly active antiretroviral therapy. Science. 1997;278(5341):1295-1300.

28. Chun TW, et al. Presence of an inducible HIV-1 latent reservoir during highly active antiretroviral therapy. Proc Natl Acad Sci US A. 1997;94(24):13193-13197.

29. Chun TW, Finzi D, Margolick J, Chadwick $\mathrm{K}$, Schwartz D, Siliciano RF. In vivo fate of HIV-1-infected T cells: quantitative analysis of the transition to stable latency. Nat Med. 1995;1(12):1284-1290.

30. Chun TW, et al. Quantification of latent tissue reservoirs and total body viral load in HIV-1 infection. Nature. 1997;387(6629):183-188.

31. Siliciano JD, et al. Long-term follow-up studies confirm the stability of the latent reservoir for HIV-1 in resting CD4+ T cells. Nat Med. 2003;9(6):727-728.

32. Crooks AM, et al. Precise quantitation of the latent HIV-1 reservoir: implications for eradication strategies. Jinfect Dis. 2015;212(9):1361-1365.

33. Hermankova M, et al. Analysis of human immunodeficiency virus type 1 gene expression in latently infected resting CD4+ Tlymphocytes in vivo. JVirol. 2003;77(13):7383-7392.

34. Yukl SA, et al. HIV latency in isolated patient $\mathrm{CD}^{+} \mathrm{T}$ cells may be due to blocks in HIV transcriptional elongation, completion, and splicing. Sci Transl Med.2018;10(430):eaap9927.

35. Telwatte S, et al. Gut and blood differ in constitutive blocks to HIV transcription, suggesting tissue-specific differences in the mechanisms that govern HIV latency. PLoS Pathog. 2018;14(11):e1007357.

36. Lassen KG, Bailey JR, Siliciano RF. Analysis of human immunodeficiency virus type 1 transcriptional elongation in resting $\mathrm{CD} 4+\mathrm{T}$ cells in vivo. JVirol. 2004;78(17):9105-9114.

37. Graf EH, et al. Gag-positive reservoir cells are susceptible to HIV-specific cytotoxic T lymphocyte mediated clearance in vitro and can be detected in vivo [corrected]. PLoS One. 2013;8(8):e71879.

38. Pardons M, et al. Single-cell characterization and quantification of translation-competent viral reservoirs in treated and untreated HIV infection. PLoS Pathog. 2019;15(2):e1007619.

39. Lassen KG, Ramyar KX, Bailey JR, Zhou Y, Sili- 
ciano RF. Nuclear retention of multiply spliced HIV-1 RNA in resting CD4+ T cells. PLoS Pathog. 2006;2(7):e68.

40. Palmer $S$, et al. New real-time reverse transcriptase-initiated PCR assay with single-copy sensitivity for human immunodeficiency virus type 1 RNA in plasma. J Clin Microbiol. 2003;41(10):4531-4536.

41. Maldarelli F, et al. ART suppresses plasma HIV-1 RNA to a stable set point predicted by pretherapy viremia. PLoS Pathog. 2007;3(4):e46.

42. Bailey JR, et al. Residual human immunodeficiency virus type 1 viremia in some patients on antiretroviral therapy is dominated by a small number of invariant clones rarely found in circulating $\mathrm{CD} 4+$ T cells. JVirol. 2006;80(13):6441-6457.

43. Sedaghat AR, Siliciano JD, Brennan TP, Wilke $\mathrm{CO}$, Siliciano RF. Limits on replenishment of the resting CD4+ T cell reservoir for HIV in patients on HAART. PLoS Pathog. 2007;3(8):e122.

44. Palmer S, et al. Low-level viremia persists for at least 7 years in patients on suppressive antiretroviral therapy. Proc Natl Acad Sci U S A. 2008;105(10):3879-3884.

45. Imamichi H, et al. Defective HIV-1 proviruses produce novel protein-coding RNA species in HIV-infected patients on combination antiretroviral therapy. Proc Natl Acad Sci U S A. 2016;113(31):8783-8788.

46. Imamichi H, et al. Defective HIV-1 proviruses produce viral proteins. Proc Natl Acad Sci U S A. 2020;117(7):3704-3710.

47. Hatano $\mathrm{H}$, et al. Cell-based measures of viral persistence are associated with immune activation and programmed cell death protein 1 (PD-1)-expressing CD4+ T cells. J Infect Dis. 2013;208(1):50-56.

48. Stunnenberg M, et al. Synthetic abortive HIV-1 RNAs induce potent antiviral immunity. Front Immunol. 2020;11:8.

49. Cheng L, et al. Blocking type I interferon signaling enhances $\mathrm{T}$ cell recovery and reduces HIV-1 reservoirs. JClin Invest. 2017;127(1):269-279.

50. Horsburgh BA, et al. High levels of genetically intact HIV in HLA-DR+ memory T cells indicates their value for reservoir studies. AIDS. 2020;34(5):659-668.

51. Finzi $D$, et al. Latent infection of CD4+ T cells provides a mechanism for lifelong persistence of HIV-1, even in patients on effective combination therapy. Nat Med.1999;5(5):512-517.

52. Whitney JB, et al. Rapid seeding of the viral reservoir prior to SIV viraemia in rhesus monkeys. Nature. 2014;512(7512):74-77.

53. Okoye AA, et al. Early antiretroviral therapy limits SIV reservoir establishment to delay or prevent post-treatment viral rebound. Nat Med. 2018;24(9):1430-1440.

54. Henrich TJ, et al. HIV-1 persistence following extremely early initiation of antiretroviral therapy (ART) during acute HIV-1 infection: An observational study. PLoS Med. 2017;14(11):e1002417.

55. Ananworanich J, et al. HIV DNA set point is rapidly established in acute HIV infection and dramatically reduced by early ART. EBioMedicine. 2016;11:68-72.

56. Leyre L, et al. Abundant HIV-infected cells in blood and tissues are rapidly cleared upon ART initiation during acute HIV infection. Sci Transl Med.2020;12(533):eaav3491.

57. Lamers SL, et al. HIV DNA is frequently present within pathologic tissues evaluated at autopsy from combined antiretroviral therapy-treated patients with undetectable viral loads. JVirol. 2016;90(20):8968-8983.

58. Chaillon A, et al. HIV persists throughout deep tissues with repopulation from multiple anatomical sources. J Clin Invest. 2020;130(4):1699-1712.

59. Wong JK, Yukl SA. Tissue reservoirs of HIV. Curr Opin HIV AIDS. 2016;11(4):362-370.

60. Estes JD, et al. Defining total-body AIDS-virus burden with implications for curative strategies. Nat Med.2017;23(11):1271-1276.

61. Chomont N, et al. HIV reservoir size and persistence are driven by $\mathrm{T}$ cell survival and homeostatic proliferation. Nat Med. 2009;15(8):893-900.

62. Shan L, et al. Transcriptional reprogramming during effector-to-memory transition renders $\mathrm{CD}_{4}{ }^{+} \mathrm{T}$ cells permissive for latent HIV-1 infection. Immunity. 2017;47(4):766-775.e3.

63. Dobrowolski C, et al. Entry of polarized effector cells into quiescence forces HIV latency. mBio. 2019;10(2):e00337-19.

64. Banga R, et al. PD-1(+) and follicular helper T cells are responsible for persistent HIV- 1 transcription in treated aviremic individuals. Nat Med. 2016;22(7):754-761.

65. Chew GM, et al. TIGIT marks exhausted T Cells, correlates with disease progression, and serves as a target for immune restoration in HIV and SIV infection. PLoS Pathog. 2016;12(1):e1005349.

66. Fromentin R, et al. CD4+ T cells expressing PD-1, TIGIT and LAG-3 contribute to HIV persistence during ART. PLoS Pathog. 2016;12(7):e1005761.

67. Evans VA, et al. Programmed cell death-1 contributes to the establishment and maintenance of HIV-1 latency. AIDS. 2018;32(11):1491-1497.

68. Fromentin R, et al. PD- 1 blockade potentiates HIV latency reversal ex vivo in $\mathrm{CD} 4^{+} \mathrm{T}$ cells from ART-suppressed individuals. Nat Commun. 2019;10(1):814.

69. Kumar NA, et al. The role of antigen presenting cells in the induction of HIV-1 latency in resting CD4(+) T-cells. Retrovirology. 2015;12:76.

70. Rezaei SD, Lu HK, Chang JJ, Rhodes A, Lewin SR, Cameron PU. The pathway to establishing HIV latency is critical to how latency is maintained and reversed. J Virol. 2018;92(13):e02225-17.

71. Stevenson M, Stanwick TL, Dempsey MP, Lamonica CA. HIV-1 replication is controlled at the level of $\mathrm{T}$ cell activation and proviral integration. ЕМВО J.1990;9(5):1551-1560.

72. Zack JA, Arrigo SJ, Weitsman SR, Go AS, Haislip A, Chen IS. HIV-1 entry into quiescent primary lymphocytes: molecular analysis reveals a labile, latent viral structure. Cell. 1990;61(2):213-222.

73. Baldauf HM, et al. SAMHD1 restricts HIV-1 infection in resting CD4(+) T cells. Nat Med. 2012;18(11):1682-1687.

74. Pace MJ, et al. Directly infected resting CD4+ T cells can produce HIV Gag without spreading infection in a model of HIV latency. PLoS Pathog. 2012;8(7):e1002818.

75. Coiras M, et al. IL-7 induces SAMHD1 phosphorylation in CD4+ T lymphocytes, improving early steps of HIV-1 life cycle. Cell Rep.
2016;14(9):2100-2107.

76. Cameron PU, et al. Establishment of HIV-1 latency in resting $\mathrm{CD} 4+\mathrm{T}$ cells depends on chemokineinduced changes in the actin cytoskeleton. Proc Natl Acad Sci U S A. 2010;107(39):16934-16939.

77. Chavez L, Calvanese V, Verdin E. HIV latency is established directly and early in both resting and activated primary CD4 T cells. PLoS Pathog. 2015;11(6):e1004955.

78. Agosto LM, Herring MB, Mothes W, Henderson AJ. HIV-1-infected CD4+ T cells facilitate latent infection of resting CD4+ T cells through cell-cell contact. Cell Rep. 2018;24(8):2088-2100.

79. Gagne M, Michaels D, Schiralli Lester GM, Gummuluru S, Wong WW, Henderson AJ. Strength of T cell signaling regulates HIV-1 replication and establishment of latency. PLoS Pathog. 2019;15(5):e1007802.

80. Evans VA, et al. Myeloid dendritic cells induce HIV-1 latency in non-proliferating CD 4+ T cells. PLoS Pathog. 2013;9(12):e1003799.

81. Belmonte $\mathrm{L}$, et al. The intestinal mucosa as a reservoir of HIV-1 infection after successful HAART. AIDS. 2007;21(15):2106-2108.

82. Chun TW, et al. Persistence of HIV in gut-associated lymphoid tissue despite long-term antiretroviral therapy. J Infect Dis. 2008;197(5):714-720.

83. Yukl SA, et al. Differences in HIV burden and immune activation within the gut of HIV-positive patients receiving suppressive antiretroviral therapy. J Infect Dis. 2010;202(10):1553-1561.

84. Churchill MJ, et al. Use of laser capture microdissection to detect integrated HIV-1 DNA in macrophages and astrocytes from autopsy brain tissues. J Neurovirol. 2006;12(2):146-152.

85. Costiniuk CT, et al. HIV persistence in mucosal $\mathrm{CD} 4+\mathrm{T}$ cells within the lungs of adults receiving long-term suppressive antiretroviral therapy. AIDS. 2018;32(16):2279-2289.

86. Carter CC, et al. HIV-1 infects multipotent progenitor cells causing cell death and establishing latent cellular reservoirs. Nat Med. 2010;16(4):446-451.

87. Durand CM, et al. HIV-1 DNA is detected in bone marrow populations containing $\mathrm{CD} 4+\mathrm{T}$ cells but is not found in purified CD34+ hematopoietic progenitor cells in most patients on antiretroviral therapy. J Infect Dis. 2012;205(6):1014-1018.

88. Ganor Y, et al. HIV-1 reservoirs in urethral macrophages of patients under suppressive antiretroviral therapy. Nat Microbiol. 2019;4(4):633-644.

89. Launay O, et al. Residual HIV-1 RNA and HIV-1 DNA production in the genital tract reservoir of women treated with HAART: the prospective ANRS EP24 GYNODYN study. Antivir Ther (Lond). 2011;16(6):843-852.

90. Deleage C, Moreau M, Rioux-Leclercq N, Ruffault A, Jégou B, Dejucq-Rainsford N. Human immunodeficiency virus infects human seminal vesicles in vitro and in vivo. Am J Pathol. 2011;179(5):2397-2408.

91. Ho YC, et al. Replication-competent noninduced proviruses in the latent reservoir increase barrier to HIV-1 cure. Cell. 2013;155(3):540-551.

92. Lee $\mathrm{GQ}$, et al. Clonal expansion of genome-intact HIV-1 in functionally polarized Th1 CD 4+ T cells. JClin Invest. 2017;127(7):2689-2696.

93. Bruner KM, et al. Defective proviruses rapidly 
accumulate during acute HIV-1 infection. Nat Med. 2016;22(9):1043-1049.

94. Vibholm LK, et al. Characterization of intact proviruses in blood and lymph node from HIVinfected individuals undergoing analytical treatment interruption. J Virol. 2019;93(8):e01920-18.

95. Kandathil AJ, Sugawara S, Balagopal A. Are T cells the only HIV-1 reservoir? Retrovirology. 2016;13(1):86.

96. Wong ME, Jaworowski A, Hearps AC. The HIV reservoir in monocytes and macrophages. Front Immunol. 2019;10:1435.

97. Baxter AE, et al. Macrophage infection via selective capture of HIV-1-infected CD4+ T cells. Cell Host Microbe. 2014;16(6):711-721.

98. Massanella M, et al. Infrequent HIV infection of circulating monocytes during antiretroviral therapy. J Virol. 2019;94(1):e01174-19.

99. Cattin A, et al. HIV-1 is rarely detected in blood and colon myeloid cells during viral-suppressive antiretroviral therapy. AIDS 2019;33(8):1293-1306.

100.Buzon MJ, et al. HIV-1 persistence in CD4+ T cells with stem cell-like properties. Nat Med. 2014;20(2):139-142.

101.Jaafoura S, et al. Progressive contraction of the latent HIV reservoir around a core of lessdifferentiated $\mathrm{CD}^{+}$memory T Cells. Nat Commun. 2014;5:5407.

102. Kulpa DA, et al. Differentiation into an effector memory phenotype potentiates HIV-1 latency reversal in $\mathrm{CD}^{+} \mathrm{T}$ cells. J Virol. 2019;93(24):e00969-19.

103. Kulpa DA, Chomont N. HIV persistence in the setting of antiretroviral therapy: when, where and how does HIV hide? J Virus Erad. 2015;1(2):59-66.

104. Hiener B, et al. Identification of genetically intact HIV-1 proviruses in specific CD $4^{+} \mathrm{T}$ cells from effectively treated participants. Cell Rep. 2017;21(3):813-822.

105. Gosselin A, et al. HIV persists in CCR6+CD4+ T cells from colon and blood during antiretroviral therapy. AIDS. 2017;31(1):35-48.

106. Cantero-Pérez J, et al. Resident memory T cells are a cellular reservoir for HIV in the cervical mucosa. Nat Commun. 2019;10(1):4739.

107. Pardons M, Fromentin R, Pagliuzza A, Routy JP, Chomont N. Latency-reversing agents induce differential responses in distinct memory CD4 T cell subsets in individuals on antiretroviral therapy. Cell Rep. 2019;29(9):2783-2795.e5.

108. Grau-Expósito J, et al. Latency reversal agents affect differently the latent reservoir present in distinct CD4+ T subpopulations. PLoS Pathog. 2019;15(8):e1007991.

109. Wagner TA, et al. HIV latency. Proliferation of cells with HIV integrated into cancer genes contributes to persistent infection. Science. 2014;345(6196):570-573.

110. Maldarelli F, et al. HIV latency. Specific HIV integration sites are linked to clonal expansion and persistence of infected cells. Science. 2014;345(6193):179-183.

111. Lenasi T, Contreras X, Peterlin BM. Transcriptional interference antagonizes proviral gene expression to promote HIV latency. Cell Host Microbe. 2008;4(2):123-133.
112. Einkauf KB, et al. Intact HIV-1 proviruses accumulate at distinct chromosomal positions during prolonged antiretroviral therapy. J Clin Invest. 2019;129(3):988-998.

113. Verdin E, Paras P, Van Lint C. Chromatin disruption in the promoter of human immunodeficiency virus type 1 during transcriptional activation. EMBO J. 1993;12(8):3249-3259.

114. Sheridan PL, Mayall TP, Verdin E, Jones KA. Histone acetyltransferases regulate HIV-1 enhancer activity in vitro. Genes Dev. 1997;11(24):3327-3340

115. Lusic M, Marcello A, Cereseto A, Giacca M. Regulation of HIV-1 gene expression by histone acetylation and factor recruitment at the LTR promoter. EMBO J. 2003;22(24):6550-6561.

116. Coull JJ, et al. The human factors YY1 and LSF repress the human immunodeficiency virus type 1 long terminal repeat via recruitment of histone deacetylase 1. J Virol. 2000;74(15):6790-6799.

117. Archin NM, Keedy KS, Espeseth A, Dang H, Hazuda DJ, Margolis DM. Expression of latent human immunodeficiency type 1 is induced by novel and selective histone deacetylase inhibitors. AIDS. 2009;23(14):1799-1806.

118. Friedman J, et al. Epigenetic silencing of HIV-1 by the histone $\mathrm{H} 3$ lysine 27 methyltransferase enhancer of Zeste 2. J Virol. 2011;85(17):9078-9089.

119. Kauder SE, Bosque A, Lindqvist A, Planelles $\mathrm{V}$, Verdin E. Epigenetic regulation of HIV-1 latency by cytosine methylation. PLoS Pathog. 2009;5(6):e1000495.

120. Chougui G, et al. HIV-2/SIV viral protein X counteracts HUSH repressor complex. Nat Microbiol. 2018;3(8):891-897.

121. Yurkovetskiy L, et al. Primate immunodeficiency virus proteins Vpx and Vpr counteract transcriptional repression of proviruses by the HUSH complex. Nat Microbiol. 2018;3(12):1354-1361.

122. Kao SY, Calman AF, Luciw PA, Peterlin BM. Anti-termination of transcription within the long terminal repeat of HIV-1 by tat gene product. Nature. 1987;330(6147):489-493.

123. Van Lint C, Amella CA, Emiliani S, John M, Jie $\mathrm{T}$, Verdin E. Transcription factor binding sites downstream of the human immunodeficiency virus type 1 transcription start site are important for virus infectivity. J Virol.1997;71(8):6113-6127.

124. Barboric M, Nissen RM, Kanazawa S, JabraneFerrat N, Peterlin BM. NF-kappaB binds P-TEFb to stimulate transcriptional elongation by RNA polymerase II. Mol Cell. 2001;8(2):327-337.

125. Wei P, Garber ME, Fang SM, Fischer WH, Jones KA. A novel CDK9-associated C-type cyclin interacts directly with HIV-1 Tat and mediates its high-affinity, loop-specific binding to TAR RNA. Cell.1998;92(4):451-462.

126. Purcell DF, Martin MA. Alternative splicing of human immunodeficiency virus type $1 \mathrm{mRNA}$ modulates viral protein expression, replication, and infectivity. J Virol. 1993;67(11):6365-6378.

127. Houzet L, Yeung ML, de Lame V, Desai D, Smith SM, Jeang KT. MicroRNA profile changes in human immunodeficiency virus type (HIV-1) seropositive individuals. Retrovirology. 2008;5:118.

128. Chiang K, Liu H, Rice AP. miR-132 enhances HIV-1 replication. Virology. 2013;438(1):1-4.
129. Huang J, et al. Cellular microRNAs contribute to HIV-1 latency in resting primary CD4+ T lymphocytes. Nat Med. 2007;13(10):1241-1247.

130. Ahluwalia JK, et al. Human cellular microRNA hsa-miR-29a interferes with viral nef protein expression and HIV-1 replication. Retrovirology. 2008;5:117.

131. Chomont N, DaFonseca S, Vandergeeten C, Ancuta P, Sékaly RP. Maintenance of CD4+ T-cell memory and HIV persistence: keeping memory, keeping HIV. Curr Opin HIV AIDS. 2011;6(1):30-36.

132. Cohn LB, et al. HIV-1 integration landscape during latent and active infection. Cell. 2015;160(3):420-432.

133. von Stockenstrom S, et al. Longitudinal genetic characterization reveals that cell proliferation maintains a persistent HIV type 1 DNA pool during effective HIV therapy. J Infect Dis. 2015;212(4):596-607.

134. Simonetti FR, et al. Clonally expanded CD4+ T cells can produce infectious HIV-1 in vivo. Proc Natl Acad Sci U S A. 2016;113(7):1883-1888.

135. Bui JK, et al. Proviruses with identical sequences comprise a large fraction of the replication-competent HIV reservoir. PLoS Pathog. 2017;13(3):e1006283.

136. Wiegand A, et al. Single-cell analysis of HIV-1 transcriptional activity reveals expression of proviruses in expanded clones during ART. Proc Natl Acad Sci U S A. 2017;114(18):E3659-E3668.

137. Wang Z, et al. Expanded cellular clones carrying replication-competent HIV-1 persist, wax, and wane. Proc Natl Acad Sci U S A. 2018;115(11):E2575-E2584.

138. Coffin JM, et al. Clones of infected cells arise early in HIV-infected individuals. JCI Insight. 2019;4(12):128432

139. Pinzone MR, et al. Longitudinal HIV sequencing reveals reservoir expression leading to decay which is obscured by clonal expansion. Nat Commun. 2019;10(1):728.

140. Josefsson L, et al. The HIV-1 reservoir in eight patients on long-term suppressive antiretroviral therapy is stable with few genetic changes over time. Proc Natl Acad Sci U S A. 2013;110(51):E4987-E4996.

141. Gantner P, et al. Drug resistance and tropism as markers of the dynamics of HIV-1 DNA quasispecies in blood cells of heavily pretreated patients who achieved sustained virological suppression. J Antimicrob Chemother. 2016;71(3):751-761.

142. Kim M, Siliciano RF. Reservoir expansion by T-cell proliferation may be another barrier to curing HIV infection. Proc Natl Acad Sci U S A. 2016;113(7):1692-1694.

143. Henrich TJ, et al. Human immunodeficiency virus type 1 persistence following systemic chemotherapy for malignancy. J Infect Dis. 2017;216(2):254-262.

144. Mendoza P, et al. Antigen responsive CD4+ T cell clones contribute to the HIV-1 latent reservoir [preprint]. https://doi. org/10.1101/2020.01.10.902155. Posted on bioRxiv January 11, 2020.

145. Hosmane NN, et al. Proliferation of latently infected $\mathrm{CD} 4{ }^{+} \mathrm{T}$ cells carrying replicationcompetent HIV-1: Potential role in latent reservoir 
dynamics. JExp Med. 2017;214(4):959-972.

146.Cesana D, et al. HIV-1-mediated insertional activation of STAT5B and BACH2 trigger viral reservoir in T regulatory cells. Nat Commun. 2017;8(1):498.

147. Murray AJ, Kwon KJ, Farber DL, Siliciano RF. The latent reservoir for HIV-1: how immunologic memory and clonal expansion contribute to HIV-1 persistence. J Immunol. 2016;197(2):407-417.

148.Pitman MC, Lau JSY, McMahon JH, Lewin SR. Barriers and strategies to achieve a cure for HIV. Lancet HIV. 2018;5(6):e317-e328.

149. Kim Y, Anderson JL, Lewin SR. Getting the "kill” into "shock and kill": strategies to eliminate latent HIV. Cell Host Microbe. 2018;23(1):14-26.

150. Hamer DH. Can HIV be cured? Mechanisms of HIV persistence and strategies to combat it. Curr HIV Res. 2004;2(2):99-111.

151. Ait-Ammar A, et al. Current status of latency reversing agents facing the heterogeneity of HIV-1 cellular and tissue reservoirs. Front Microbiol. 2019;10:3060.

152. Prins JM, et al. Immuno-activation with anti-CD3 and recombinant human IL-2 in HIV-1-infected patients on potent antiretroviral therapy. AIDS. 1999;13(17):2405-2410.

153. Wei DG, et al. Histone deacetylase inhibitor romidepsin induces HIV expression in CD4 T cells from patients on suppressive antiretroviral therapy at concentrations achieved by clinical dosing. PLoS Pathog. 2014;10(4):e1004071.

154. Tsai $P$, et al. In vivo analysis of the effect of panobinostat on cell-associated HIV RNA and DNA levels and latent HIV infection. Retrovirology. 2016;13(1):36

155. Bartholomeeusen K, Fujinaga K, Xiang Y, Peterlin BM. Histone deacetylase inhibitors (HDACis) that release the positive transcription elongation factor $\mathrm{b}(\mathrm{P}-\mathrm{TEFb})$ from its inhibitory complex also activate HIV transcription. J Biol Chem . 2013;288(20):14400-14407.

156. Martínez-Bonet M, Clemente MI, Serramía MJ, Muñoz E, Moreno S, Muñoz-Fernández MÁ. Synergistic activation of latent HIV-1 expression by novel histone deacetylase inhibitors and bryostatin-1. Sci Rep. 2015;5:16445.

157. Williams SA, et al. Prostratin antagonizes HIV latency by activating NF-kappaB.J Biol Chem. 2004;279(40):42008-42017.

158. Spina CA, et al. An in-depth comparison of latent HIV-1 reactivation in multiple cell model systems and resting CD4+ T cells from aviremic patients. PLoS Pathog. 2013;9(12):e1003834.

159. Bullen CK, Laird GM, Durand CM, Siliciano JD, Siliciano RF. New ex vivo approaches distinguish effective and ineffective single agents for reversing HIV-1 latency in vivo. Nat Med. 2014;20(4):425-429.

160. Laird GM, et al. Ex vivo analysis identifies effective HIV-1 latency-reversing drug combinations. J Clin Invest. 2015;125(5):1901-1912.

161. Jiang G, et al. Synergistic reactivation of latent HIV expression by ingenol-3-angelate, PEP005, targeted NF-kB signaling in combination with JQ1 induced p-TEFb activation. PLoS Pathog. 2015;11(7):e1005066.

162. Darcis G, et al. An in-depth comparison of latencyreversing agent combinations in various in vitro and ex vivo HIV-1 latency models identified bryostatin-1+JQ1 and ingenol-B+JQ1 to potently reactivate viral gene expression. PLoS Pathog. 2015;11(7):e1005063.

163. Campbell GR, Bruckman RS, Chu YL, Trout $\mathrm{RN}$, Spector SA. SMAC mimetics induce autophagy-dependent apoptosis of HIV-1-infected resting memory CD4+ T cells. Cell Host Microbe. 2018;24(5):689-702.e7.

164. Pache L, et al. BIRC2/cIAP1 is a negative regulator of HIV-1 transcription and can be targeted by Smac mimetics to promote reversal of viral latency. Cell Host Microbe. 2015;18(3):345-353.

165. Nixon CC, et al. Systemic HIV and SIV latency reversal via non-canonical NF- $\kappa \mathrm{B}$ signalling in vivo. Nature. 2020;578(7793):160-165.

166. Lim SY, et al. TLR7 agonists induce transient viremia and reduce the viral reservoir in SIVinfected rhesus macaques on antiretroviral therapy. Sci Transl Med. 2018;10(439):eaao4521.

167. Macedo AB, et al. Dual TLR2 and TLR7 agonists as HIV latency-reversing agents. JCI Insight. 2018;3(19):122673.

168. Huang L, Pardee AB. Suberoylanilide hydroxamic acid as a potential therapeutic agent for human breast cancer treatment. Mol Med. 2000;6(10):849-866.

169. Richon VM, et al. A class of hybrid polar inducers of transformed cell differentiation inhibits histone deacetylases. Proc Natl Acad Sci U S A. 1998;95(6):3003-3007.

170.Madrid-Elena N, et al. Maraviroc is associated with latent HIV-1 reactivation through $\mathrm{NF}-\kappa \mathrm{B}$ activation in resting $\mathrm{CD} 4^{+} \mathrm{T}$ cells from HIVinfected individuals on suppressive antiretroviral therapy. J Virol. 2018;92(9):e01931-17.

171. Archin NM, et al. Valproic acid without intensified antiviral therapy has limited impact on persistent HIV infection of resting CD4+ T cells. AIDS. 2008;22(10):1131-1135.

172. Archin NM, et al. Antiretroviral intensification and valproic acid lack sustained effect on residual HIV-1 viremia or resting CD4+ cell infection. PLoS One. 2010;5(2):e9390.

173. Routy JP, et al. Valproic acid in association with highly active antiretroviral therapy for reducing systemic HIV-1 reservoirs: results from a multicentre randomized clinical study. HIV Med. 2012;13(5):291-296.

174. Sagot-Lerolle N, et al. Prolonged valproic acid treatment does not reduce the size of latent HIV reservoir. AIDS. 2008;22(10):1125-1129.

175. Siliciano JD, et al. Stability of the latent reservoir for HIV-1 in patients receiving valproic acid. J Infect Dis. 2007;195(6):833-836.

176. Archin NM, et al. Administration of vorinostat disrupts HIV-1 latency in patients on antiretroviral therapy. Nature. 2012;487(7408):482-485.

177. Elliott JH, et al. Activation of HIV transcription with short-course vorinostat in HIV-infected patients on suppressive antiretroviral therapy. PLoS Pathog. 2014;10(10):e1004473.

178. Archin NM, et al. Interval dosing with the HDAC inhibitor vorinostat effectively reverses HIV latency. J Clin Invest. 2017;127(8):3126-3135.

179. Rasmussen TA, et al. Panobinostat, a histone deacetylase inhibitor, for latent-virus reactivation in $\mathrm{HIV}$-infected patients on suppressive antiretroviral therapy: a phase $1 / 2$, single group, clinical trial. Lancet HIV. 2014;1(1):e13-e21.

180.Søgaard OS, et al. The depsipeptide romidepsin reverses HIV-1 latency in vivo. PLoS Pathog. 2015;11(9):e1005142.

181. Gutiérrez C, et al. Bryostatin-1 for latent virus reactivation in HIV-infected patients on antiretroviral therapy. AIDS. 2016;30(9):1385-1392.

182. Trautmann L, et al. Upregulation of PD-1 expression on HIV-specific CD8+ T cells leads to reversible immune dysfunction. Nat Med. 2006;12(10):1198-1202.

183. Jones RB, et al. Histone deacetylase inhibitors impair the elimination of HIV-infected cells by cytotoxic T-lymphocytes. PLoS Pathog. 2014;10(8):e1004287.

184. Boucau J, Das J, Joshi N, Le Gall S. Latency reversal agents modulate HIV antigen processing and presentation to CD8 T cells. PLoS Pathog. 2020;16(3):e1008442.

185. Ren Y, et al. BCL-2 antagonism sensitizes cytotoxic T cell-resistant HIV reservoirs to elimination ex vivo. J Clin Invest. 2020;130(5):2542-2559.

186.Sengupta S, Siliciano RF. Targeting the latent reservoir for HIV-1. Immunity. 2018;48(5):872-895

187. Vargas B, et al. Inhibitors of signaling pathways that block reversal of HIV-1 latency. Antimicrob Agents Chemother. 2019;63(2):e01744-18.

188. Mousseau G, Kessing CF, Fromentin R, Trautmann L, Chomont N, Valente ST. The Tat inhibitor didehydro-cortistatin A prevents HIV-1 reactivation from latency. mBio. 2015;6(4):e00465.

189.Vázquez-García I, et al. Clonal heterogeneity influences the fate of new adaptive mutations. Cell Rep. 2017;21(3):732-744.

190.Xiao Q, Guo D, Chen S. Application of CRISPR/ Cas9-based gene editing in HIV-1/AIDS therapy. Front Cell Infect Microbiol. 2019;9:69.

191. Bialek JK, et al. Targeted HIV-1 latency reversal using CRISPR/Cas9-derived transcriptional activator systems. PLoS One. 2016;11(6):e0158294.

192.Zhu W, et al. The CRISPR/Cas9 system inactivates latent HIV-1 proviral DNA. Retrovirology. 2015;12:22.

193. Ueda S, Ebina H, Kanemura Y, Misawa N, Koyanagi Y. Anti-HIV-1 potency of the CRISPR/Cas9 system insufficient to fully inhibit viral replication. Microbiol Immunol. 2016;60(7):483-496.

194. Wang G, Zhao N, Berkhout B, Das AT. CRISPRCas 9 can inhibit HIV-1 replication but NHEJ repair facilitates virus escape. Mol Ther. 2016;24(3):522-526.

195. Wang Z, et al. CRISPR/Cas9-derived mutations both inhibit HIV-1 replication and accelerate viral escape. Cell Rep. 2016;15(3):481-489.

196. Yoder KE, Bundschuh R. Host double strand break repair generates HIV-1 strains resistant to CRISPR/Cas9. Sci Rep. 2016;6:29530.

197. Yin C, et al. In vivo excision of HIV-1 provirus by saCas 9 and multiplex single-guide RNAs in animal models. Mol Ther. 2017;25(5):1168-1186.

198.Cohn LB, et al. Clonal CD $4^{+}$T cells in the HIV-1 latent reservoir display a distinct gene profile upon reactivation. Nat Med. 2018;24(5):604-609.

199. Baxter AE, et al. Single-cell characterization of viral translation-competent reservoirs in HIV-infected individuals. Cell Host Microbe. 2016;20(3):368-380. 